This item was submitted to Loughborough's Research Repository by the author.

Items in Figshare are protected by copyright, with all rights reserved, unless otherwise indicated.

\title{
Factors affecting the formation and properties of wet compacts
}

PLEASE CITE THE PUBLISHED VERSION

PUBLISHER

(C) Elsevier

VERSION

AM (Accepted Manuscript)

LICENCE

CC BY-NC-ND 4.0

REPOSITORY RECORD

Wakeman, Richard J., M.N. Sabri, and E.S. Tarleton. 2009. "Factors Affecting the Formation and Properties of Wet Compacts”. figshare. https://hdl.handle.net/2134/5670. 
This item was submitted to Loughborough's Institutional Repository (https://dspace.lboro.ac.uk/) by the author and is made available under the following Creative Commons Licence conditions.

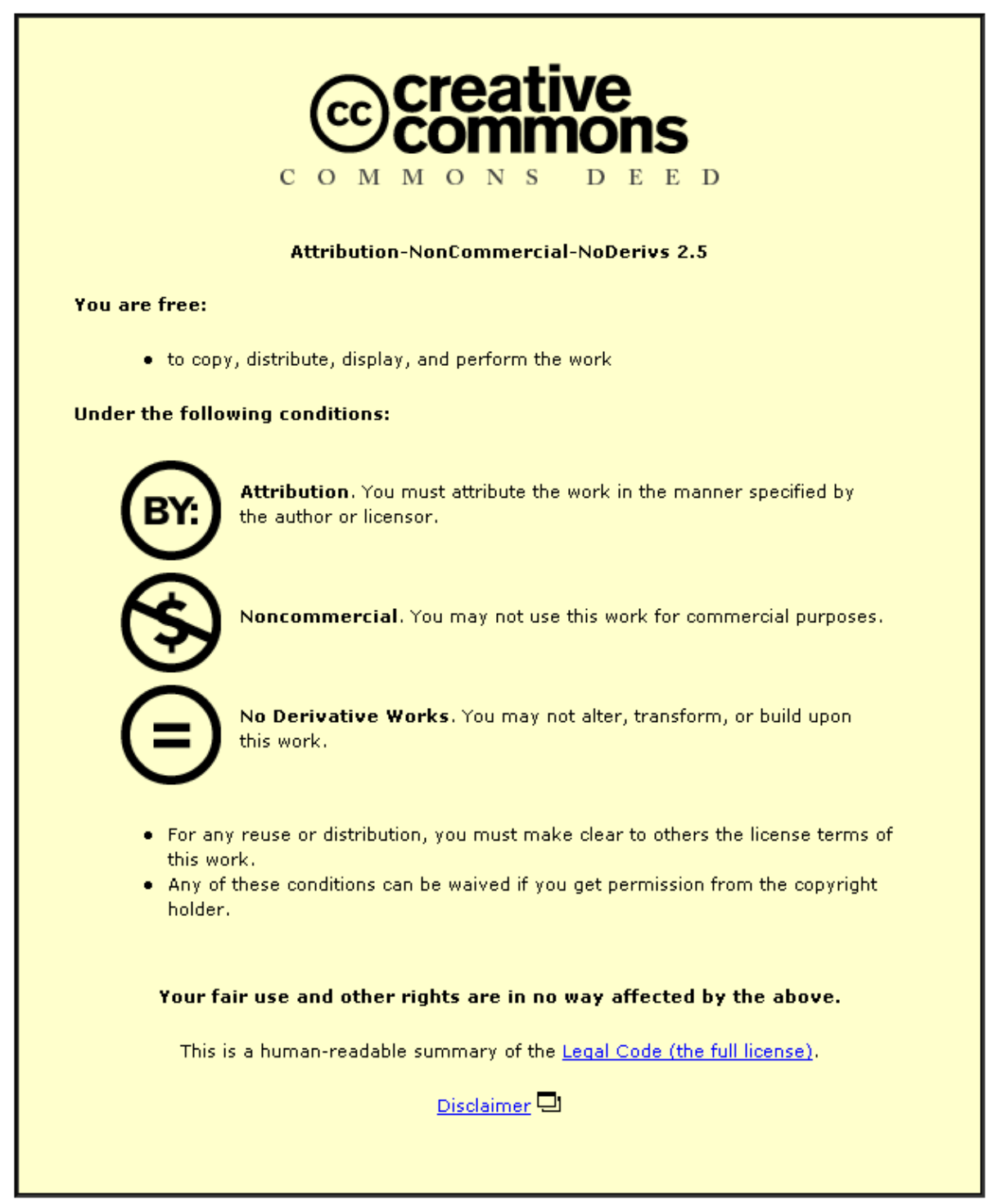

For the full text of this licence, please go to: http://creativecommons.org/licenses/by-nc-nd/2.5/ 


\title{
FACTORS AFFECTING THE FORMATION AND PROPERTIES OF WET COMPACTS
}

\author{
R.J. Wakeman, M.N. Sabri and E.S. Tarleton (e.s.tarleton@lboro.ac.uk) \\ Separation Processes Centre, University of Exeter, Exeter, UK.
}

\begin{abstract}
New data are reported on the formation of wet compacts from slurries. The compaction data are analysed through two consecutive mechanisms, filtration and consolidation. Process design parameters for each mechanism are obtained from the models which might allow calculations to be made from small-scale experiments. The magnitude and dependence of the constitutive parameters on pressure, $\mathrm{pH}$ and surface charge, particle size and shape, and the nature of the particle-particle interactions are shown through the experimental results.
\end{abstract}

\section{INTRODUCTION}

In the process engineering-related literature, there is much data which reports the compression characteristics of solid/liquid mixtures; much of this has been collated by Shirato et al. ${ }^{1}$. The main drawback with these earlier experiments is that none report all the relevant data pertaining to the particles and their solution environment, and it is therefore not possible to know which properties of the mixture affect compression. There is similarly a considerable amount of data in the colloid science literature (see, for example, in Hunter ${ }^{2,3}$ or Ottewill ${ }^{4}$ ) which has generally been obtained using 'ideal' particles (such as latices), and naturally greater emphasis has been placed upon the packing state of the particles and the formulation of interparticle forces. These works have given considerable insight into the fundamental parameters, but have not yielded engineering or design data of practical significance. The experimental work here was therefore aimed at providing an understanding of the effects of fundamental properties on design data obtained for particulates which have some industrial significance. Some details of the experimental procedures and the wider implications of basic particle properties on laboratory studies and solid/liquid separation processes have been reported previously ${ }^{5,6}$.

This paper reports results from an experimentally based study of the compression of solid/liquid mixtures which have been characterised in respect of their particle size and shape, the surface charge on the particles and the resulting aggregation of the particulate phase, and the phase compositions of the mixture. The surface charge and state of aggregation are interpreted through the $\mathrm{pH}$, although the relationships between electrophoretic mobility (and hence zeta potential) and $\mathrm{pH}$ were measured for each suspension studied.

\section{EXPERIMENTAL APPROACH AND PROCEDURE}

Studies of intermolecular forces require the highest degree of cleanliness and care because of the unpredictable behaviour of impurities on the primary mechanism. A mild detergent solution was used to clean all equipment, which was then thoroughly rinsed with twice-distilled water prior to the start of an experiment.

The particles used were anatase (supplied by Tioxide plc), china clay (ECC International Ltd), calcite and hydromagnesite (BDH Chemicals Ltd). Their sizes were measured using a Malvern Autosizer $2 \mathrm{c}$ or Coulter Counter as appropriate according to the size of the particles, and their zeta potentials determined using a Malvern Zetasizer 2c. Their general shape was checked by scanning electron microscope examinations. 
The suspensions were prepared by dispersing the particles in twice-distilled water $\left(2 \mathrm{xH}_{2} \mathrm{O}\right)$, shaken vigorously by a flask shaker, and the particles allowed to settle before any excess liquid was decanted off. This process of washing and decanting using twice-distilled water was repeated until a constant solution conductivity was reached. The solids volume fraction was then adjusted to that required for the experiment, and the $\mathrm{pH}$ altered by the addition of $\mathrm{HCl}$ or $\mathrm{NaOH}$. The $\mathrm{pH}$ was varied over as wide a range as the solid would allow without reaction taking place; in most instances, this enabled experiments from around the point of zero charge to close to the charge maximum or minimum.

The finer particle suspensions were prepared from coarse material by milling. Particle suspensions were prepared as described above before being wet ground in cleaned 5 litre porcelain ball mills containing $2.2 \mathrm{~kg}$ of porcelain balls of diameter about $10 \mathrm{~mm}$. These ground suspensions were boiled and washed with $2 \mathrm{xH}_{2} \mathrm{O}^{5}$.

The particles used in this work and their quantitative characteristics are summarised in Table 1. Apart from being of industrial interest, the selection of the particles for study was also based on their relative properties, so that particles of differing shape, size and surface charge were used.

\section{EXPERIMENTAL EQUIPMENT}

The apparatus, illustrated in Figure 1, comprised an upright, polished stainless steel cylinder mounted on a circular base. The cylinder had an internal bore of $43 \mathrm{~mm}$ and a height of $193 \mathrm{~mm}$ and was filled by suspension at the start of a test, so that different compact thicknesses were formed by starting the experiment with a different concentration of suspension. The base contained a $43 \mathrm{~mm}$ diameter recess into which a loosely fitting stainless steel sinter disc was inserted; this disc supported a porous membrane onto which the compact was deposited. A drain carried away liquid expelled from the solid/liquid mixture. A piston, actuated by a pneumatic cylinder, was used to force liquid from the cylinder. A load cell, mounted in the end of the piston, was used to monitor the force exerted onto the suspension. This assembly is referred to as the piston press in the following.

During an experiment, a rotary encoder measured the downward displacement of the piston, and enabled determination of the volume of liquid displaced from the cylinder (and hence calculation of the solids volume fraction of the mixture remaining in the cylinder). These measurements were checked by monitoring simultaneously the expelled liquid volume on a digital scale connected to a multichannel chart recorder. A timer, synchronised with the encoder, enabled the rate of piston movement to be evaluated.

The piston was driven by one of two pneumatic cylinders; the smaller allowed pressures in the range 0.3 to $3.5 \mathrm{MPa}$ to be exerted on the solid/liquid mixture, and the larger was capable of providing 6 to $40 \mathrm{MPa}$ (the maximum pressure used was limited to $20 \mathrm{MPa}$ by the installed load cell and the strength of the sintered disc). Each experiment was carried out at a constant pressure (as applied to the mixture).

\section{RELEVANT THEORY}

The theory used to analyse the experimental data to give design information was largely developed by Shirato et al. ${ }^{7}$, and is summarised below together with the inclusion of some refinements and additions. The compression of a stable suspension is made up of two parts: an initial stage in which filtration to form a cake occurs, followed by a consolidation stage during which the bulk volume of the deposited cake is reduced. If the starting suspension is unstable, the combined processes of filtration and sedimentation are responsible for the initial stage. In the experiments reported here, the initial stage was completed in a much shorter time than it took the suspension to 
sediment in a gravity field; the effects of sedimentation were therefore neglected in subsequent analyses.

\section{General Treatment of the Experimental Data}

Data are available from the piston press as the thickness of the solid/liquid mixture as a function of pressing time, and as the volume of liquid expressed as a function of time. These data can be converted one to the other, and as such serve to check that a material balance is preserved during the experiment and that there was no malfunction of the measuring apparati. The thickness of the solid/liquid mixture in the cylinder at any time is

$L=\frac{V(0)-V}{A}$

where $V(0)$ is the volume of suspension in the piston press at the start of the test and $L$ is the thickness of compact/suspension when a volume $V$ of filtrate has been removed. The mass fraction of solids in the press is converted into the solids volume fraction using

$\varepsilon_{s}=\frac{M_{s} \rho}{\left(1-M_{s}\right) \rho_{s}+M_{s} \rho}$

where $M_{s}$ is the mass fraction of solids in the mixture, $\rho$ is the liquid density and $\rho_{s}$ is the solids density. The thickness of suspension in the press and the solids volume fraction at any time are related to conditions at any other time by

$$
\left(\varepsilon_{s} L\right)_{t 1}=\left(\varepsilon_{s} L\right)_{t 2}
$$

The ratio of the mass of wet compact per unit mass of dry compact $m$ is related to the volume fraction of solids in the compact $\varepsilon_{s}$ by

$$
m=1+\frac{\rho\left(1-\varepsilon_{s}\right)}{\rho_{s} \varepsilon_{s}}
$$

and the ratio of the mass of feed slurry to the mass of solids in the feed $1 / s$ is obtained by applying eqn. (4) to the feed suspension. The 'compact' thickness at the transition from filtration to consolidation is obtained from

$L_{1}=\left(\frac{m_{1}-1}{\rho}+\frac{1}{\rho_{s}}\right) \rho_{s} \omega_{0}$

where $m_{1}$ is the ratio of the mass of wet compact to the mass of dry compact $\left(M_{s 1}{ }^{-1}\right)$ at the end of the filtration period and $\omega_{0}$ is the volume of solids in the press per unit area. The value of $m_{1}$ cannot be measured experimentally during a test, and so is estimated from the known characteristics of constant pressure filtration. The transition from filtration to consolidation mechanisms occurs when the solid/liquid mixture has a thickness of $L_{1}$. On a plot of $-\Delta L / \Delta t^{0.5}$ against $t$, constant pressure filtration data should be represented by a horizontal line (it is better to use logarithmic scales for this plot so that data scatter does not hide the transition point). When the concentration of solids in the mixture exceeds a limiting value, the mixture passes into a semisolid state and from thereon it is consolidated and the value of $-\Delta L / \Delta t^{0.5}$ decreases; at the end of the consolidation process, it reaches a value of zero. It may sometimes take a long time for the true equilibrium to be established, and hence for the end of the process to be reached. The transition point for the mixture under test, $L_{1}$, is determined from the graph as the point where - 
$\Delta L / \Delta t^{0.5}$ starts to decrease rapidly. These points are shown in Figure 2, which is a plot of a typical set of experimental data.

\section{Analysis of the First Stage; Compact Formation}

The equation describing the filtration period is the conventional filtration equation

$\frac{1}{A} \frac{d V}{d t}=\frac{A \Delta p}{\mu(\alpha c V+A R)}$

However, the integrated form of this equation is generally more convenient to use, as the expelled liquid data are usually collected as volumes rather than flow rates. The integrated form of eqn. (6) at constant pressure is

$$
\frac{t-t_{i}}{V-V_{i}}=\frac{K_{1}}{2}\left(V+V_{i}\right)+K_{2}
$$

where $K_{1}=\alpha c \mu / A^{2} \Delta p$ and $K_{2}=\mu R / A \Delta p$. Plotting the data from the filtration stage as $\left(t-t_{i}\right) /\left(V-V_{i}\right)$ against $\left(V+V_{i}\right)$ leads to a straight line from which the compact formation properties characterising the rate of the first stage of compression may be evaluated; when the start of filtration coincides with the start of the integration $t_{i}=V_{i}=0$. The effective concentration of solids in the feed to be used in eqns. (6) and (7) is given by

$$
c=\frac{\rho s}{1-m s}
$$

where $m$ is evaluated at the transition from slurry filtration to cake consolidation, i.e. $m=m_{1}$. The data shown in Figure 2 are replotted on Figure 3; compact formation is taking place over the first part of the plot, and the pronounced increase of the slope is seen where compact consolidation takes place.

\section{Analysis of the Second Stage: Compact Consolidation}

The consolidation period, $L<L_{1}$, is analysed through the use of an empirical relationship relating the consolidation ratio

$$
U_{c}=\frac{L_{1}-L}{L_{1}-L_{\infty}}
$$

to a dimensionless consolidation time defined by

$$
T_{c}=\frac{i^{2} C_{e} t_{c}}{\omega_{0}^{2}}
$$

where $i$ is the number of drainage surfaces, $C_{e}$ is a 'modified' consolidation coefficient and $t_{c}$ is the consolidation time $\left(t_{c}=0\right.$ at $U_{c}=0$, i.e. at $\left.L=L_{1}\right)$. Sivaram and Swamee ${ }^{8}$ developed a parametric expression which approximated the solution to the Terzaghi ${ }^{9,10}$ model to within $3 \%$, and that relationship was slightly modified by Shirato et al. ${ }^{7}$ to 
$U_{c}=\frac{\sqrt{4 T_{c} / \pi}}{\left(1+\left(\sqrt{4 T_{c} / \pi}\right)^{v}\right)^{1 / 2 v}}$

where $v$ is the consolidation behaviour index which takes secondary consolidation effects into account. The Sivaram and Swamee ${ }^{8}$ equation takes no account of the effects of creep and the behaviour index was assigned a constant value of 2.85. The rationale for $v=2.85$ was simply that it fitted the Terzaghi model equations, but experimental data suggest $v>2.85$ is a reality.

A value for $C_{e}$ is obtained from the initial slope of the plot of $U_{c}$ vs. $t_{c}^{0.5}$. For $T_{c} \ll 1$,

$$
U_{c}=\sqrt{\frac{4}{\pi} T_{c}}
$$

and

$$
K_{e}=(\text { slope })^{2}=\frac{4 i^{2} C_{e}}{\pi \omega_{0}^{2}}
$$

from which $C_{e}$ is calculated. A plot of the experimental data shown in Figures 2 and 3 but for $L<$ $L_{1}$, together with the fit of eqn. (11) to the data, is given in Figure 4. The agreement between theory and experiment shown here is typical of all the results which demonstrated consolidation behaviour.

\section{EXPERIMENTAL RESULTS}

Before considering the effects of fundamental properties of the solid/liquid systems on design parameters, several qualitative observations can be made.

Particle size has a major effect on compaction, which becomes more difficult and more protracted as size is reduced; for example, $15 \mu \mathrm{m}$ calcite particles in a 0.09 volume fraction suspension were fully compacted within $20 \mathrm{~s}$, whilst a $3 \mu \mathrm{m}$ suspension required $2000 \mathrm{~s}$ under the same conditions. Only a few experiments were carried out with the coarser calcite particles, as clearly these are not a problem to compact and gravity settling made a significant contribution to the formation of the compact. As the particle size is decreased, interparticle repulsive forces become appreciable compared with gravitational and imposed mechanical forces, and the permeability of the compact is lower. The final moisture content of the compact is affected to only a small extent by particle size, provided that the imposed force is sufficiently large to overcome the repulsive forces. The effect of suspension concentration was to modify the rate of expression, with lower rates being found at higher concentrations. This is largely due to the more rapid formation of a thicker compact, thereby causing the resistance to liquid flow to increase faster during the compaction process. There were no significant effects of concentration on the final packing density of the compacts; most experiments showed the initial concentration to alter the final solids packing density to within $4 \%$ of the mean value measured for the set of experiments, and feed concentration is therefore considered to be of only secondary importance.

Compaction pressure was found to have a large effect on some suspensions, but a fairly minor one on others. In general terms, higher pressures lead to the more rapid formation of more densely packed compacts, but such statements must be qualified by the magnitude of the surface charge on the particles. Two examples of the effects of pressure are shown in Figures 5 and 6 . Figure 6 shows pressure affecting the rate of compaction to a much greater extent than it does the final packing density, whereas Figure 5 shows the converse with the final solids volume fraction being 
affected to a much greater extent than the rate of compaction. The reasons for these different behaviours lie with the range over which the interparticle forces extend. Hydromagnesite is a composite of $\mathrm{MgCO}_{3}, \mathrm{Mg}(\mathrm{OH})_{2}$ and water of hydration and the magnitude of the pressures existing between the particles at high separation distances ( $\sim 300 \mathrm{~nm}$ at 0.4 volume fraction) presents a problem which might only be explained by (i) a double layer charge being given by the lattice charge of the mineral or (ii) a thick layer of structural water over the particle surface. The diffuse double layer then originates at this distance from the surface. The lattice charge would need to correspond to a much higher surface potential than zeta potential measurements would suggest. It is difficult to reconcile the magnitude of the interparticle pressures observed with expectations from double layer theory when considering the hydromagnesite data.

Effects of $\mathrm{pH}$ on compaction were found to vary according to the magnitude of the surface charge on the particles. Calcite had a low zeta potential $(<|20| \mathrm{mV})$ and the repulsive forces are correspondingly low. As might be expected, calcite data showed negligible effects of $\mathrm{pH}$ on either the rate of compaction or the final porosity of the compact. At the other extreme, the magnitude of the zeta potential of anatase (up to $\sim|60| \mathrm{mV}$ ) caused marked changes in the rate of compaction, as shown on Figure 7. Most rapid compaction occurred at the point of zero charge, whereas at greater (either positive or negative) zeta potentials the rate of compaction was reduced. At the lower $\mathrm{pH}$ shown on Figure 7, the ionic strength is high, thereby causing suppression of the double layer and a reduction in the magnitude of the repulsive force. The effects of $\mathrm{pH}$ (through the double layer thickness) on the final packing density appeared to be small in comparison with the effects demonstrated by the surface of hydromagnesite.

It is interesting to note the different general shapes of the curves on Figure 7 in comparison with those on Figures 5 and 6 . The extreme forms on Figure 5 are indicative of a long period of compact consolidation, whereas those on Figure 7 occur when there is no contribution from the compact consolidation mechanism.

\section{DISCUSSION OF RESULTS}

The data shown on Figures 5 and 6 for the hydromagnesite and chin a clay suspensions are replotted according to eqn. (7) on Figures 8 and 9, and some analogous data for anatase suspensions are shown on Figure 10. These plots also indicate the sharp transition from filtration to consolidation for the anatase data, compared with the more gradual change or the hydromagnesite. The gradient on the initial portion of these plots is proportional to the specific resistance per unit pressure difference $(\alpha / \Delta p)$ of the deposit being formed; in all cases, the gradient decreases less rapidly than the applied pressure increases, resulting in an increase of specific resistance with applied pressure.

Experimental data from the piston press were available in the form of the volume of liquid expelled $(V)$ or the piston displacement as a function of time $(t)$. From these data and the conditions of the experiment, it was necessary to evaluate the specific cake resistance $(\alpha)$ during the filtration stage of the compression process, and the modified consolidation coefficient $\left(\mathrm{C}_{\mathrm{e}}\right)$ and the behaviour index $(v)$ during the consolidation stage. These are the factors to be used in any subsequent design calculations. The voids ratio $(e)$ in equilibrium with the applied pressure gives a measure of the limiting packing density achievable at that pressure. From analyses of several compression tests carried out at different pressures in the piston press, the parameters $\alpha$ and voids ratio can be plotted as functions of the applied pressure $\Delta p$. Useful expressions for these purposes are only valid over a specified pressure range and take the form:

$$
\begin{aligned}
& \alpha=\alpha_{0} p^{n} \\
& e=e_{0}-b \log p
\end{aligned}
$$


where $\alpha_{0}, n, e_{0}$ and $b$ are coefficients of the solid/liquid system of interest, $\alpha$ is the specific resistance of the deposit formed during the filtration stage and $e$ is the voids ratio of the compact at the end of the compression process. Typical examples of the $\alpha$ vs. $p$ relationships are shown on Figures 11 and 12, illustrating the decrease in permeability associated with smaller particle sizes and higher applied pressures. The permeability similarly decreases when the particles are better dispersed; changing the $\mathrm{pH}$ of the china clay suspension from $2.9(\zeta \approx-15 \mathrm{mV})$ to $10.2(\zeta \approx-57 \mathrm{mV})$ increases the specific resistance by a factor of about one order of magnitude.

Examples of the e vs. $p$ relationships are shown on Figures 13 and 14. pH or surface charge appears to have no effect on the equilibrium voids ratio at these higher pressures, but reducing the particle size (at a constant $\mathrm{pH}$ ) results in a higher equilibrium voids ratio. This is presumably a manifestation of the greater charge density around the surface of the finer particles.

The coefficients characterising the compression phase of the operation, $C_{e}$ and $v$, are also known from the piston press results and may be represented by the equations

$$
\begin{aligned}
& C_{e}=C_{e 0} p^{\gamma} \\
& v=\frac{4 p}{\delta+p}
\end{aligned}
$$

Coefficients arising from applications of the constitutive equations to the experimental data are summarised in Table 2. The limiting value of $v$ at high pressures is 4 according to eqn. (17), but it is recognised that $v$ is likely to be pressure dependent at lower applied pressures or when resisting forces between the particles are unusually high.

The data in Table 2 generally show the trends which might be anticipated, but there are also some unexpected results. With the exception of calcite, the specific resistance increases and the compact voids ratio decreases with increasing pressure. Over the limited pressure range of the calcite tests, there was no detectable change in the compact permeability or specific resistance, in spite of a reduction of the voids ratio.

The less obvious results arise from consolidation of the anatase and hydromagnesite beds. For china clay the modified consolidation coefficient $\left(C_{e}\right)$ increases with pressure, with a much increased sensitivity to pressure being observed at greater $|\zeta|$-potentials, but the consolidation behaviour index $(v)$ was constant. However, for anatase both the modified consolidation coefficient and the consolidation behaviour index were found to be independent of pressure; a value of the packing density close to the limit measured at the end of the experiment was obtained whilst the filtration mechanism was effective, leaving little potential for further consolidation of the compact. The most curious result was the reduction of $C_{e}$ with increasing pressure for hydromagnesite, together with the dependence of $v$ on pressure.

The different behaviour of hydromagnesite does require further consideration, as it may be attributed to various causes. The shape of the hydromagnesite particle is similar to that of a calcite particle and not too dissimilar from that of an anatase particle, and the surface charge is similar to that at a calcite surface. However, the size of the hydromagnesite particle is much greater than that of calcite or anatase and significant surface charge effects would not be expected to arise. A notable difference between the three particle systems is their solubility in cold water: anatase is insoluble, calcite has a solubility of $0.0014 \mathrm{~g} / 100 \mathrm{ml}$, and hydromagnesite $0.04 \mathrm{~g} / 100 \mathrm{ml}$. The solubility for hydromagnesite is greater than the corresponding solubility of either the carbonate $(0.0106 \mathrm{~g} / 100 \mathrm{ml})$ or hydroxide $(0.0009 \mathrm{~g} / 100 \mathrm{ml})$ in isolation, and could be expected to increase the electrolyte concentration near to the particle surfaces. If this led to a layer of structured liquid 
over the surface of the particle, it may explain why such anomalous results were obtained. To verify the precise reasons for these results will require considerably more research.

It is perhaps worth pointing out the effects of increasing the surface charge on the compaction process. Comparisons between the calcite and china clay data are particularly suitable for this: for calcite $\zeta \approx-16 \mathrm{mV}$ at $\mathrm{pH}=11.8$, and for china clay $\zeta \approx-57 \mathrm{mV}$ at $\mathrm{pH}=10.2$ and $\zeta \approx-15 \mathrm{mV}$ at $\mathrm{pH}=$ 2.9. The effect of charge alone is seen by comparing the china clay at $\mathrm{pH} 10.2$ and 2.9. The ultimate packing densities at the two pHs are not very different, as shown by the $e_{0}$ and $b$ values on Table 2 and by Figure 13, but a higher surface charge considerably increases the resistance to compact formation, shown by the $\alpha_{0}$ values in Table 2 . The effect of higher surface charges slowing the kinetics of formation is also demonstrated clearly for an unwashed anatase on Figure 7. Effects of particle shape and at $\zeta \approx|15| \mathrm{mV}$ are seen by comparing the anatase and china clay data at $\mathrm{pH} 11.8$ and 2.9, respectively; the calcite has lower resistances to compact formation and consolidation and the particles approach their ultimate packing density at only slightly lower pressures. The surface charge is more uniformly distributed around the more regularly shaped calcite than around the plate-like china clay particles whose packing can resemble the so-called 'house of cards' structure. A regular shape enables the fluid between the particles to act as a lubricant, resulting in the ability of the particles to pack closer to the ultimate value before the consolidation process occurs. Other things being equal, increasing the surface charge density around the particles leads to slower compaction by both the filtration and consolidation mechanisms.

\section{CONCLUSIONS}

The nature of the compression of fine particle suspensions is dependent on the applied pressure, $\mathrm{pH}$ and surface charge, particle size and shape and the nature of the particle-particle interactions. The form of dynamic compaction curves can vary widely, but they can all be analysed through the application of a two-stage mechanism model. The two stages, which act consecutively, are the basic filtration and consolidation processes. New data have been presented for some selected solid/liquid systems to show how the compression characteristics change with the basic and fundamental properties of the solid/liquid mixture.

\section{ACKNOWLEDGEMENTS}

The authors wish to record their gratitude for receipt of grants from the Science and Engineering Research Council Specially Promoted Programme in Particulate Technology and those companies supporting the Industrial Research Consortium of the Separation Processes Centre at Exeter University. The results presented here were obtained with assistance from those grants.

\section{LIST OF SYMBOLS}

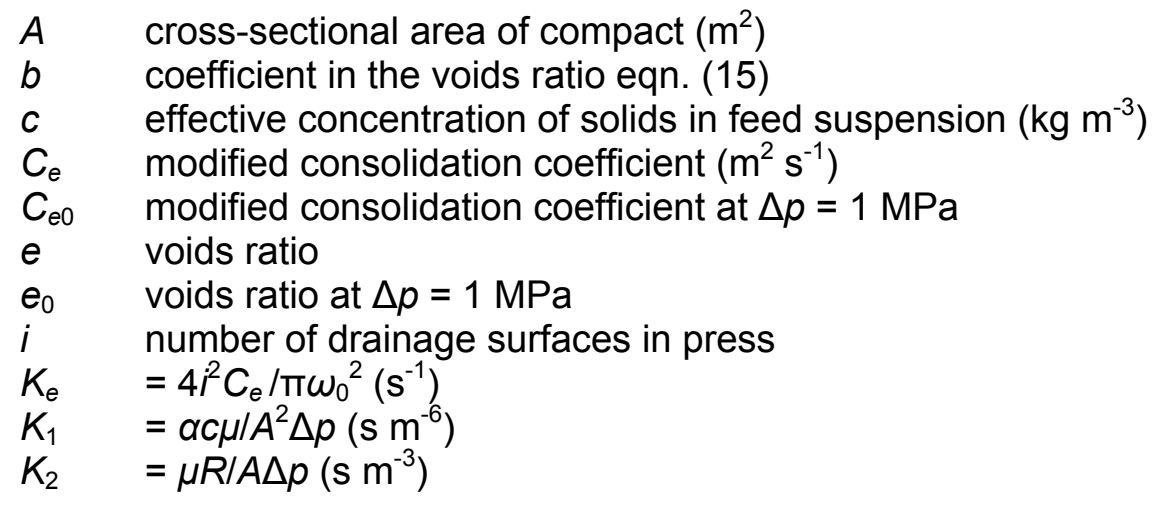




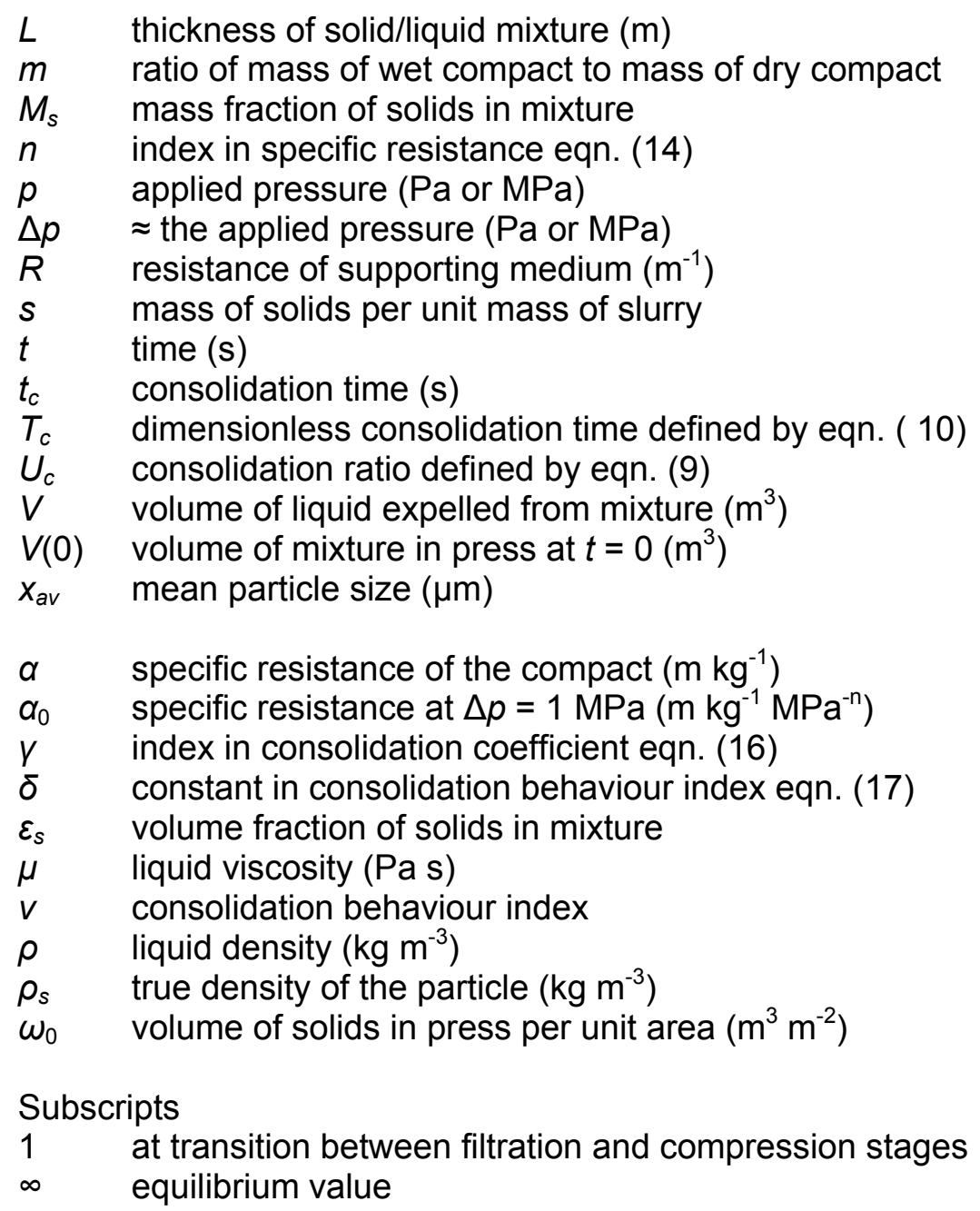

\section{REFERENCES}

1. M. Shirato, T. Murase, E. Iritani, F.M. Tiller and A.F. Alciatore, 1981, in Filtration, M.J. Matteson and C. Orr (Eds.), Marcel Dekker, New York.

2. R.J. Hunter, 1981, Zeta Potential in Colloid Science, Academic Press, London.

3. R.J. Hunter, 1987, Foundations of Colloid Science, Clarendon Press, Oxford.

4. R.H. Ottewill, 1980, Progr. Colloid \& Polymer Sci., 57, 71.

5. S.T. Thuraisingham and R.J. Wakeman, 1987, Proc. $20^{\text {th }}$ Biennial Conf. of the International Briquetting Association, 389.

6. R.J. Wakeman, S.T. Thuraisingham and E.S. Tarleton, 1989, Filtration and Separation, 26, 271.

7. M. Shirato, T. Murase and M. Iwata, 1986, in Progress in Filtration and Separation: 4, R.J. Wakeman (Ed.), Elsevier, Amsterdam.

8. B. Sivaram and P.K. Swamee, 1977, J. Japanese Soc. Soil Mech. Found. Eng., 17, 48.

9. K. Terzaghi and P.B. Peck, 1948, Soil Mechanics in Engineering Practice, Wiley, New York. 
10. D.W. Taylor, 1962, Fundamentals of Soil Mechanics, $5^{\text {th }}$ Edn., pp.225-229, Wiley, New York. 
FIGURES AND TABLES

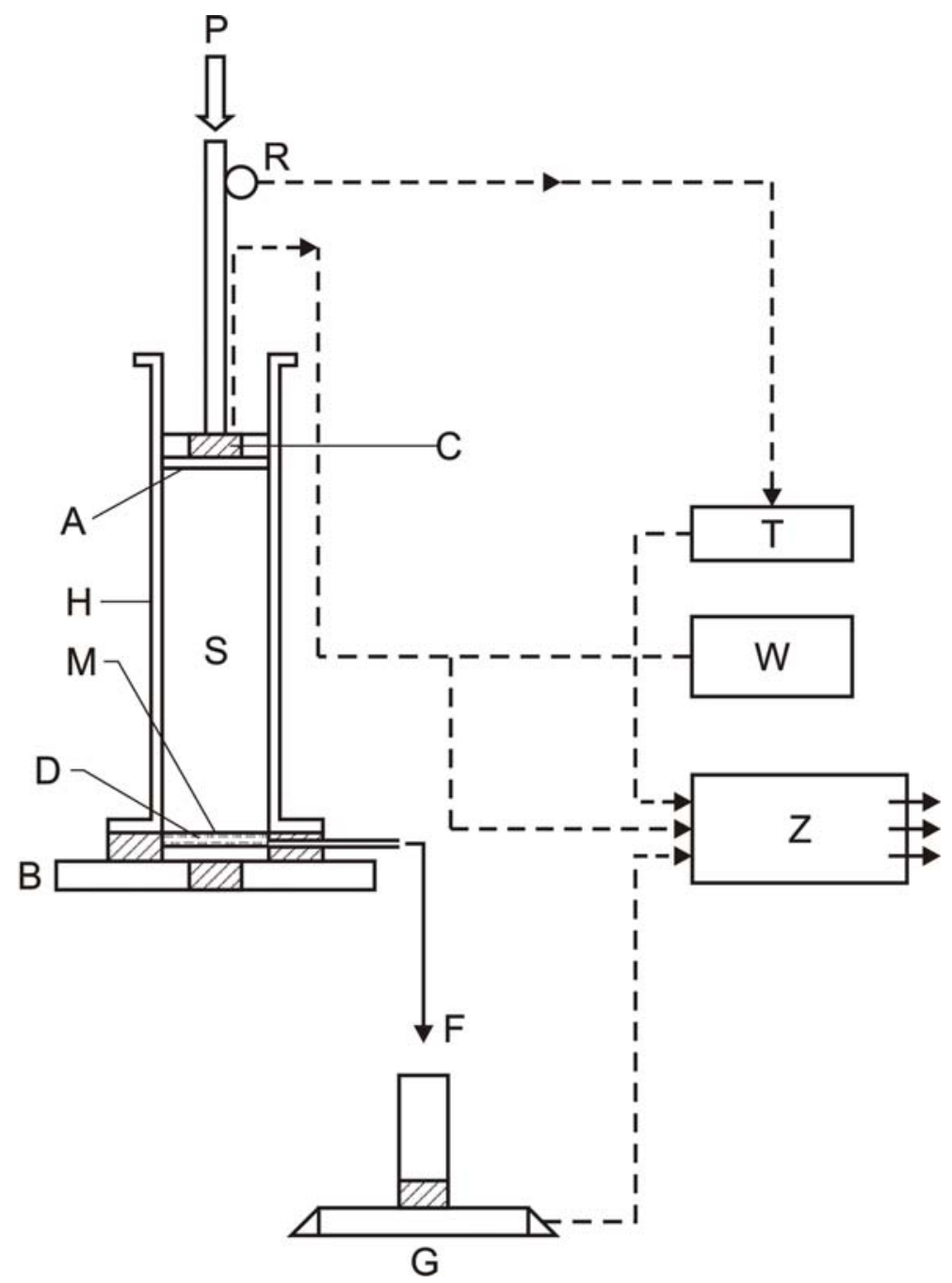

Figure 1: Line diagram of the experimental apparatus. A, piston; $B$, base; $C$, load cell; $D$, sintered disc; F, liquid discharge; $\mathrm{G}$, digital scale; $\mathrm{H}$, stainless steel cylinder; $\mathrm{M}$, membrane; $\mathrm{P}$, applied pressure; R, rotary encoder; S, solid/liquid mixture; T, timer; W, load cell power supply; Z, chart recorder. 


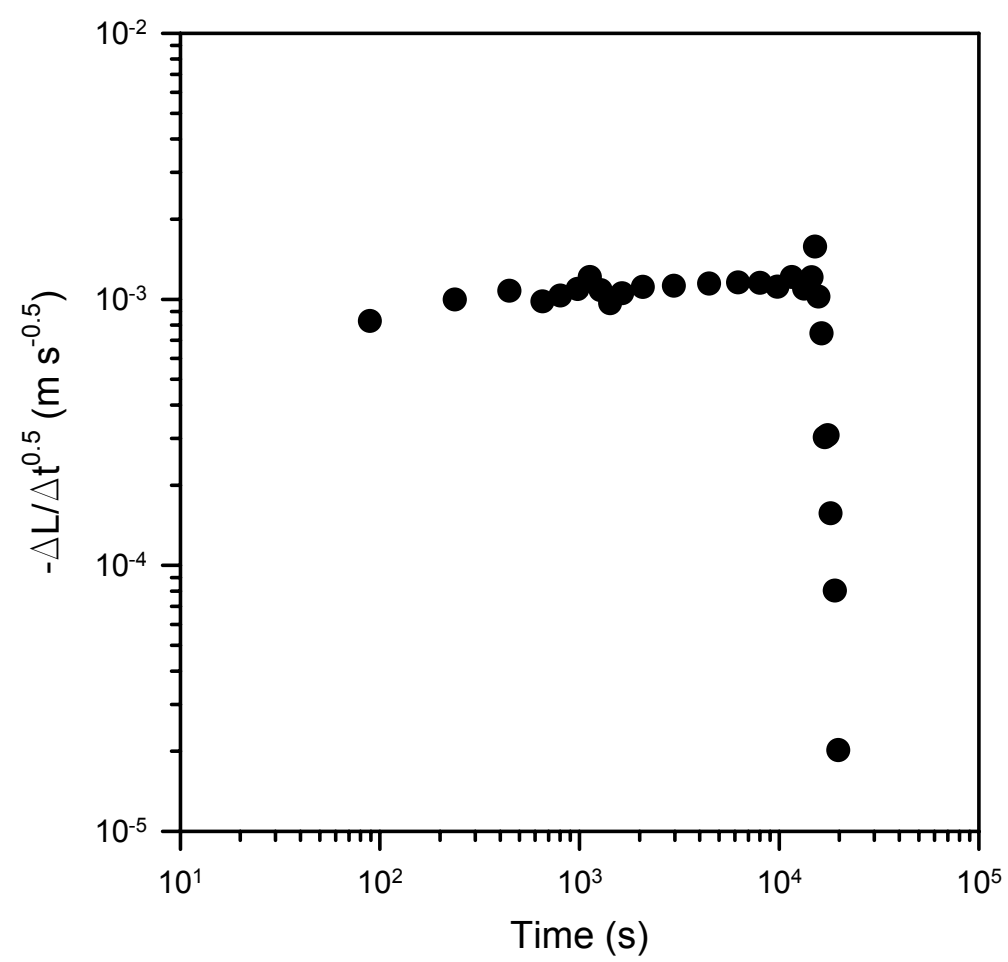

Figure 2: Identification of the filtration to consolidation point (china clay, $x_{a v}=3.3 \mu \mathrm{m}, \mathrm{pH}=5.2, p=$ 6.4 MPa).

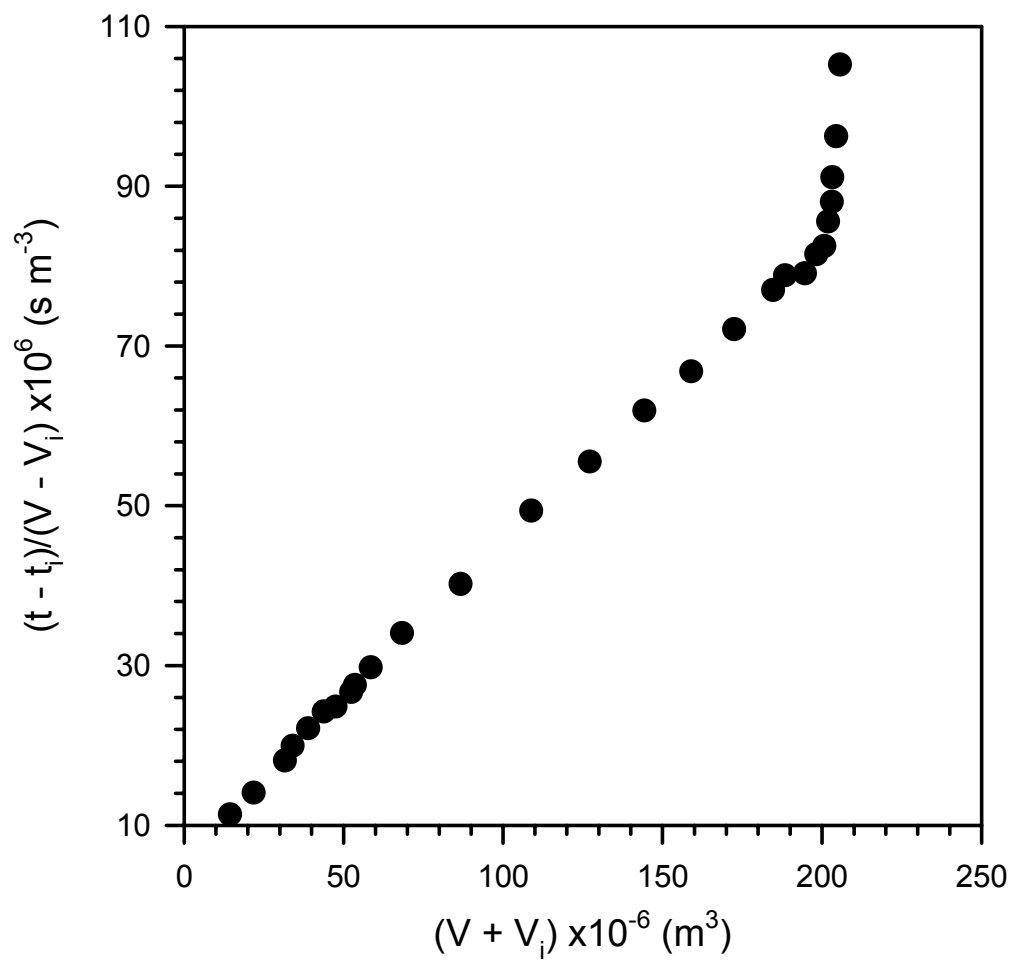

Figure 3: 'Filtration plot' of china clay experimental data $\left(x_{a v}=3.3 \mu \mathrm{m}, \mathrm{pH}=5.2, p=6.4 \mathrm{MPa}\right)$. 


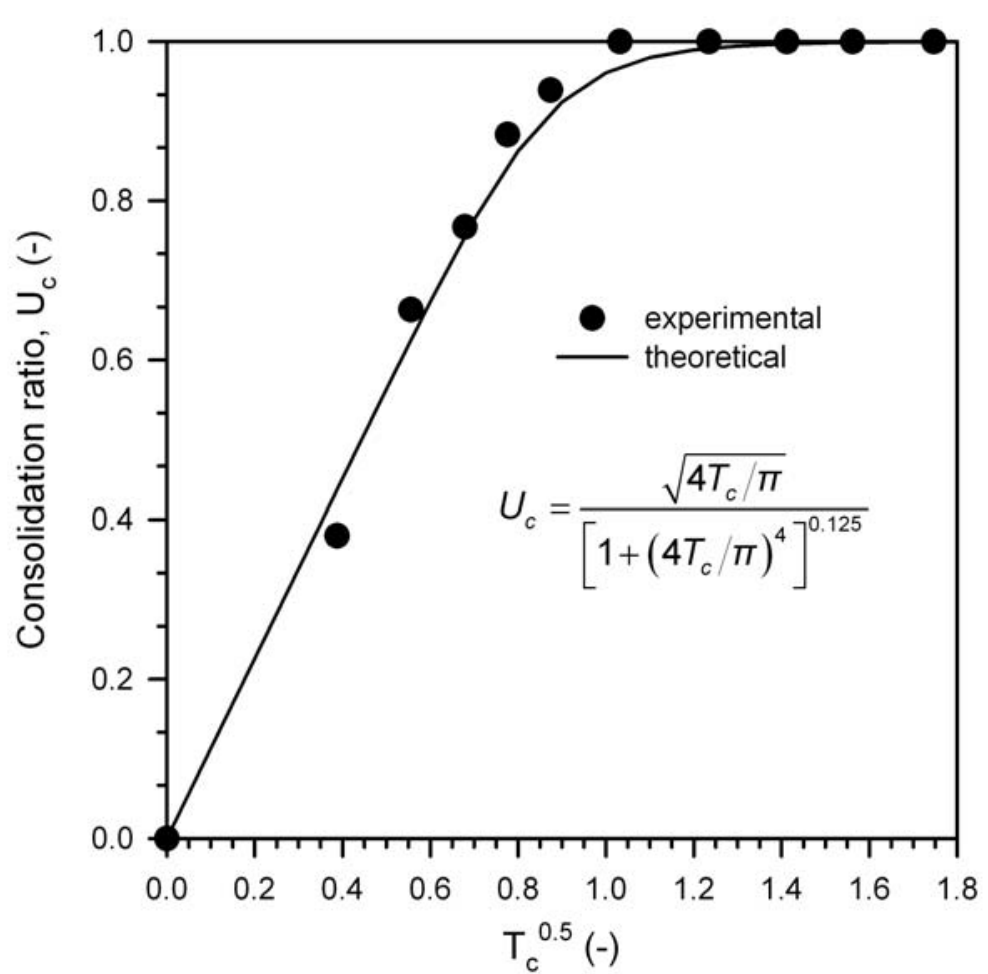

Figure 4: 'Consolidation plot' of china clay experimental data $\left(x_{a v}=3.3 \mu \mathrm{m}, \mathrm{pH}=5.2, p=6.4 \mathrm{MPa}\right)$.

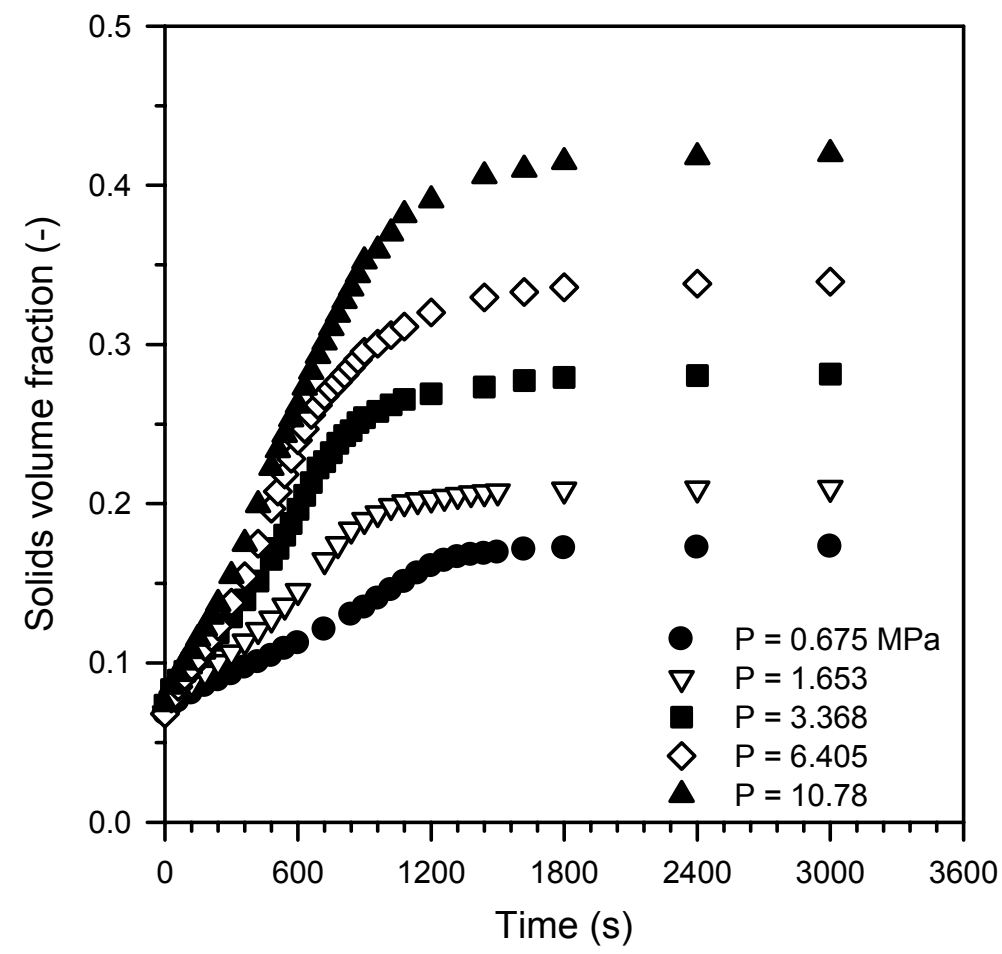

Figure 5: Effect of pressure on hydromagnesite suspension compression ( $x_{a v}=16.4 \mu \mathrm{m}, \mathrm{pH}=9.9$ ). 


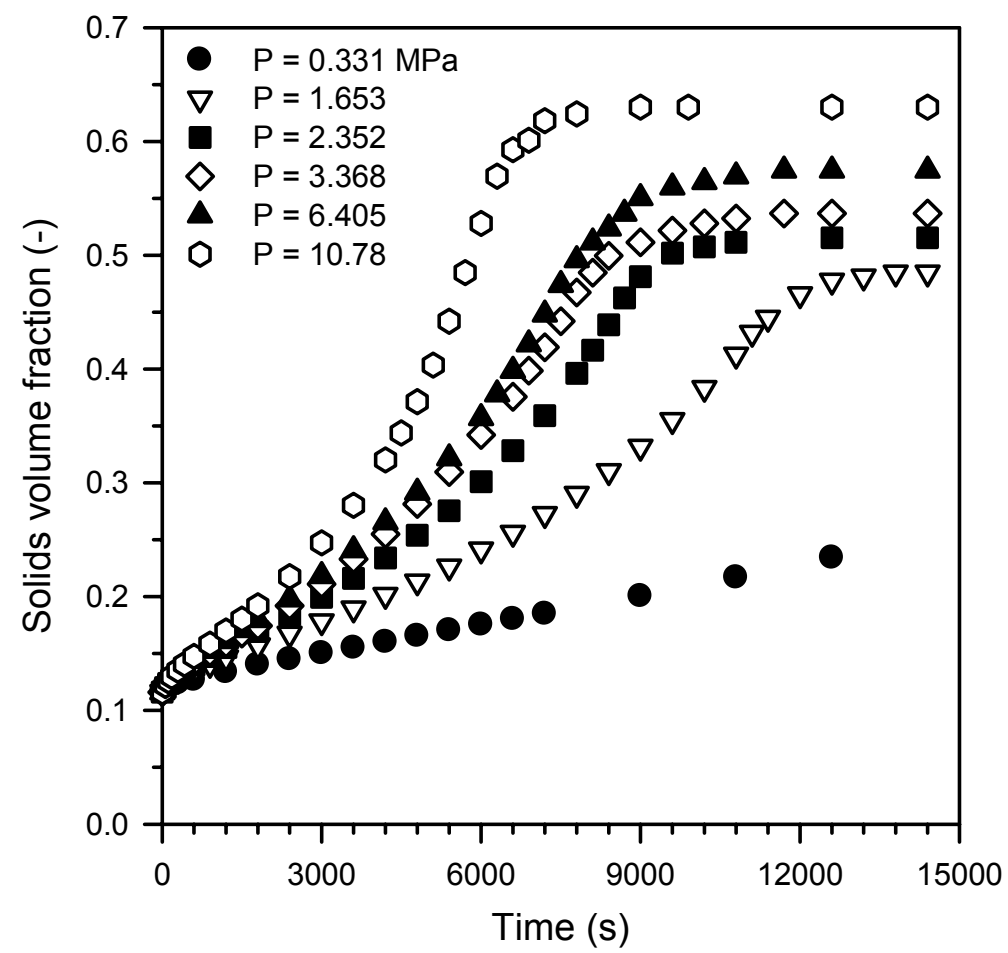

Figure 6: Effect of pressure on china clay suspension compression $\left(x_{a v}=5.4 \mu \mathrm{m}, \mathrm{pH}=5.2\right)$.

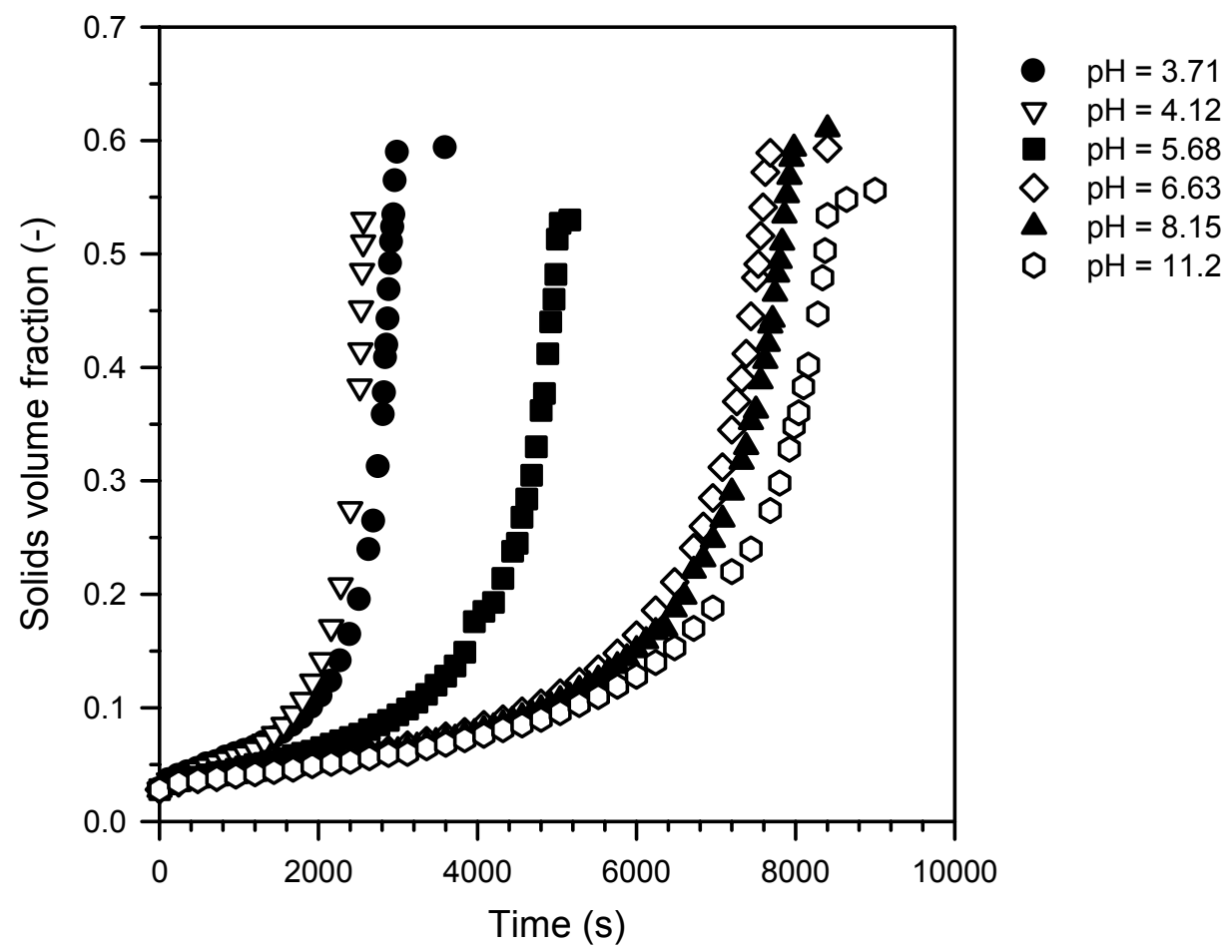

Figure 7: Effect of $\mathrm{pH}$ on unwashed anatase suspension compression $\left(x_{a v}=0.3 \mu \mathrm{m}\right.$, isoelectric $\mathrm{pH}$ $\approx 4, p=2.7 \mathrm{MPa}$ ). 


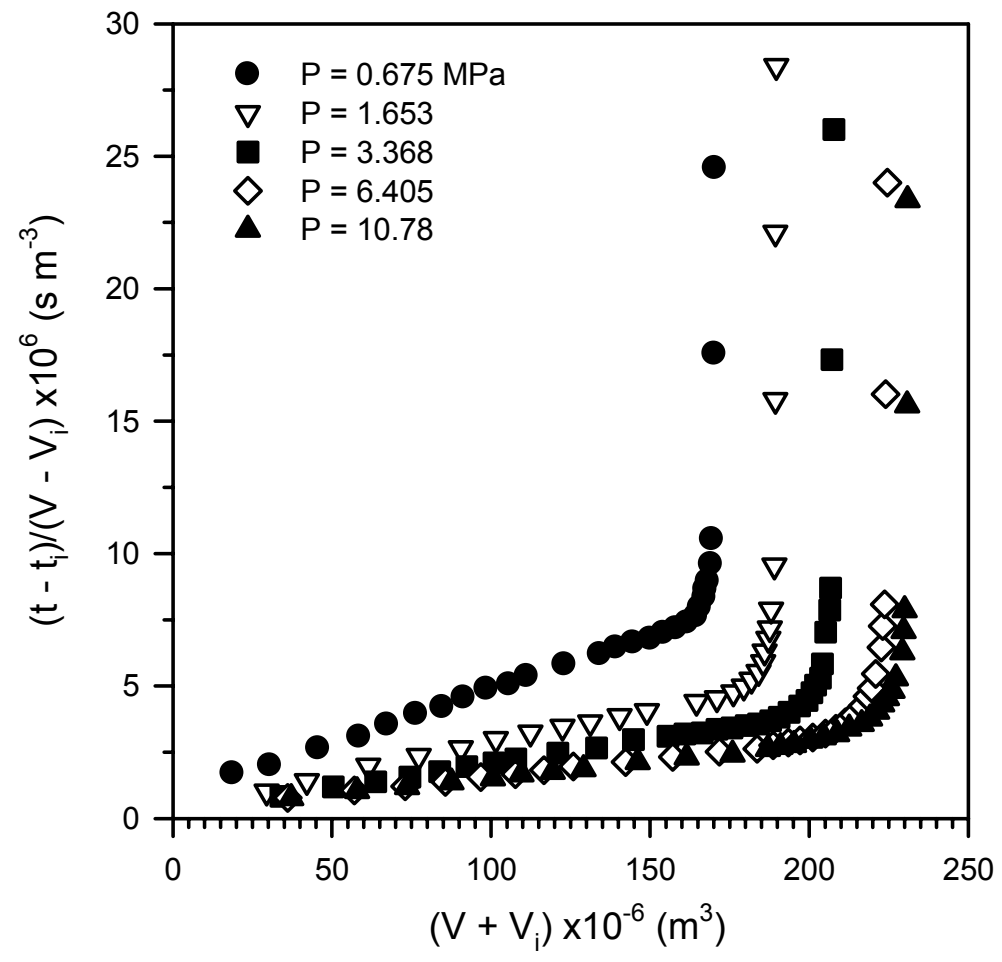

Figure 8: Effect of pressure on 'filtration plot' of hydromagnesite experimental data $\left(x_{a v}=16.4 \mu \mathrm{m}\right.$, $\mathrm{pH}=9.9)$.

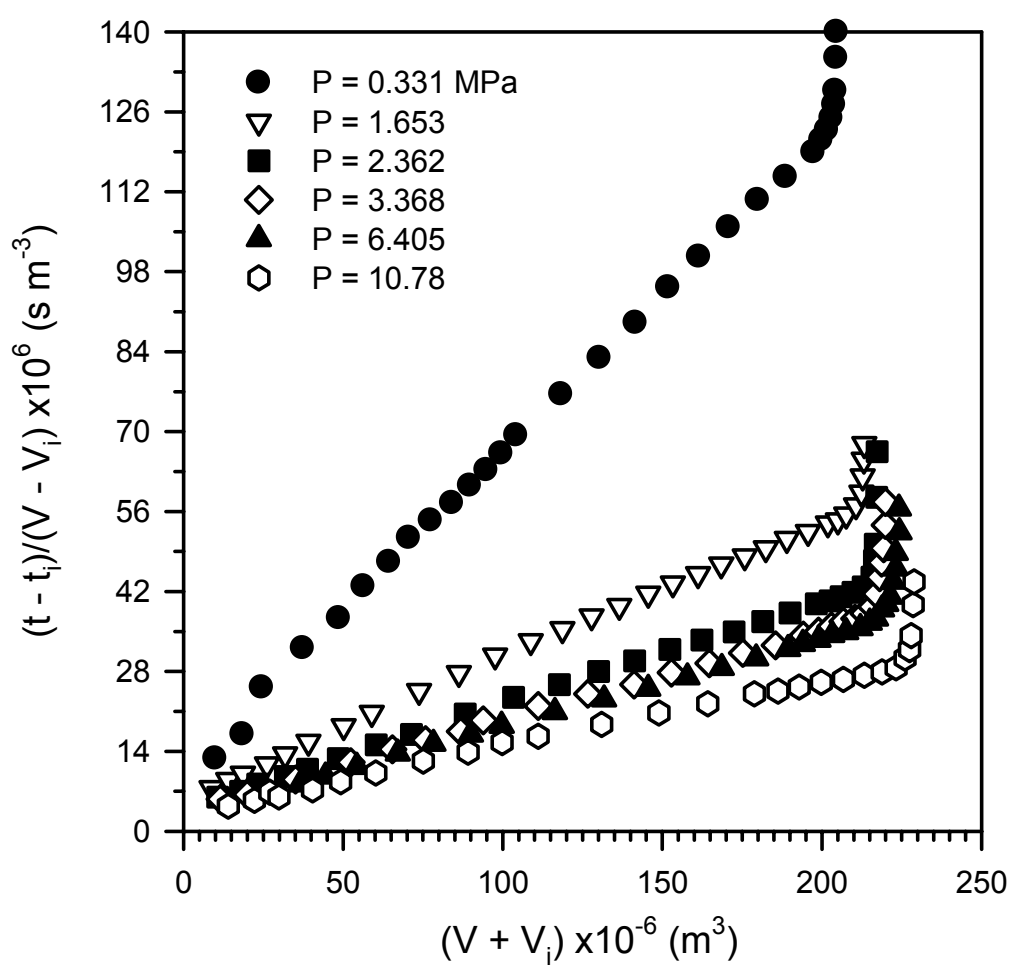

Figure 9: Effect of pressure on 'filtration plot' of china day experimental data $\left(x_{a v}=5.4 \mu \mathrm{m}, \mathrm{pH}=\right.$ $5.2)$. 


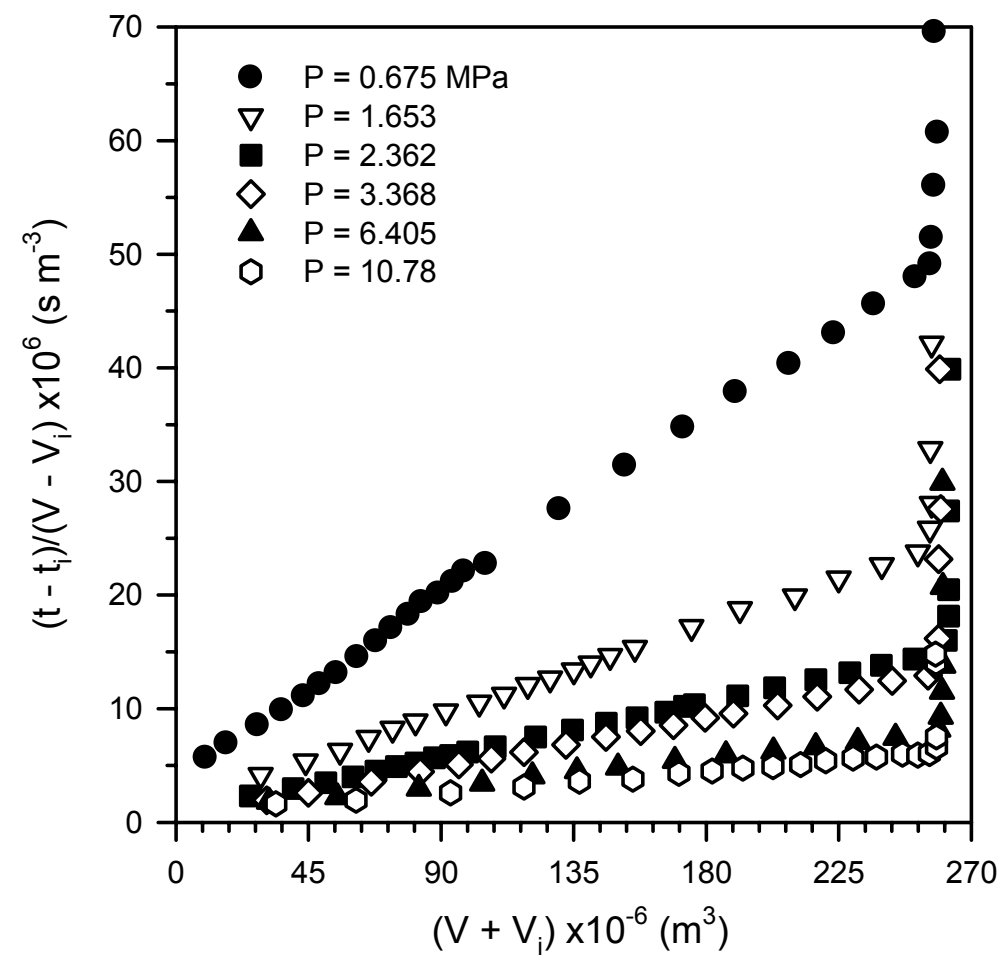

Figure 10: Effect of pressure on 'filtration plot' of anatase experimental data $\left(x_{a v}=0.3 \mu \mathrm{m}, \mathrm{pH}=4\right.$ (isoelectric point)).

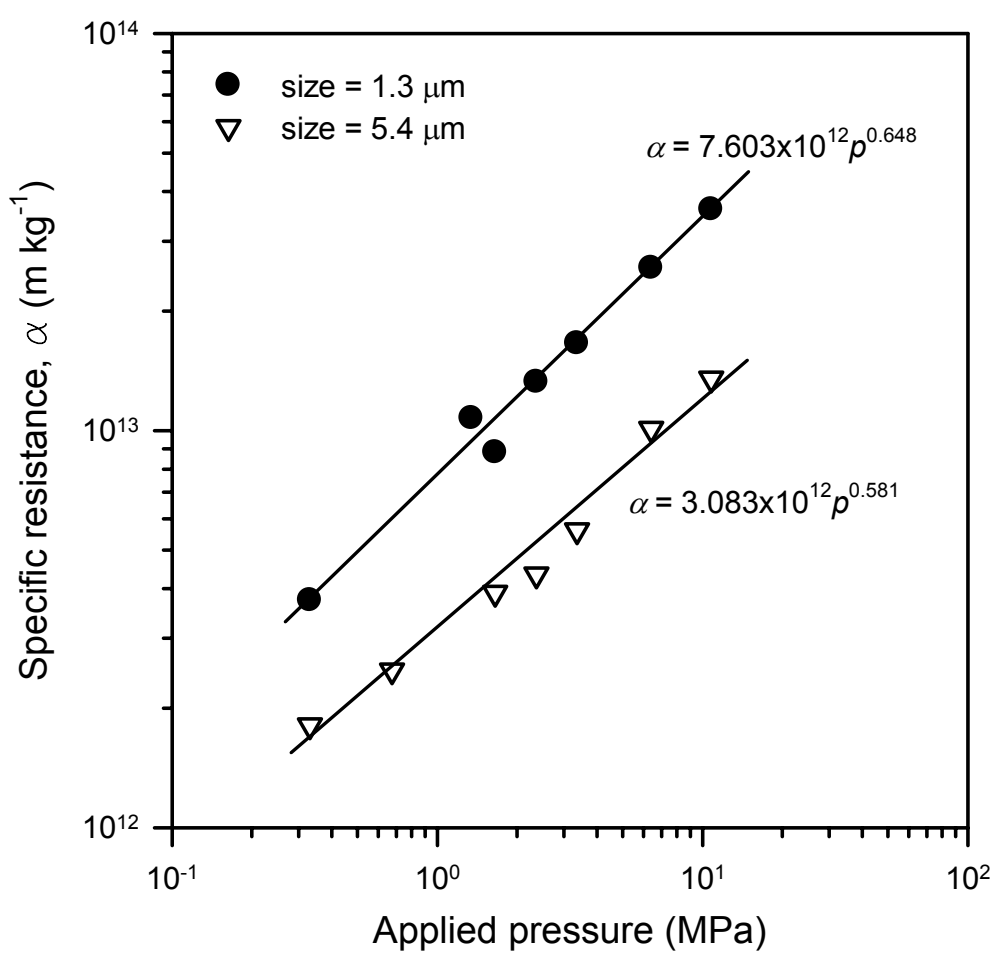

Figure 11: Dependence of specific resistance of china clay on pressure and particle size $(\mathrm{pH}=$ $5.2)$. 


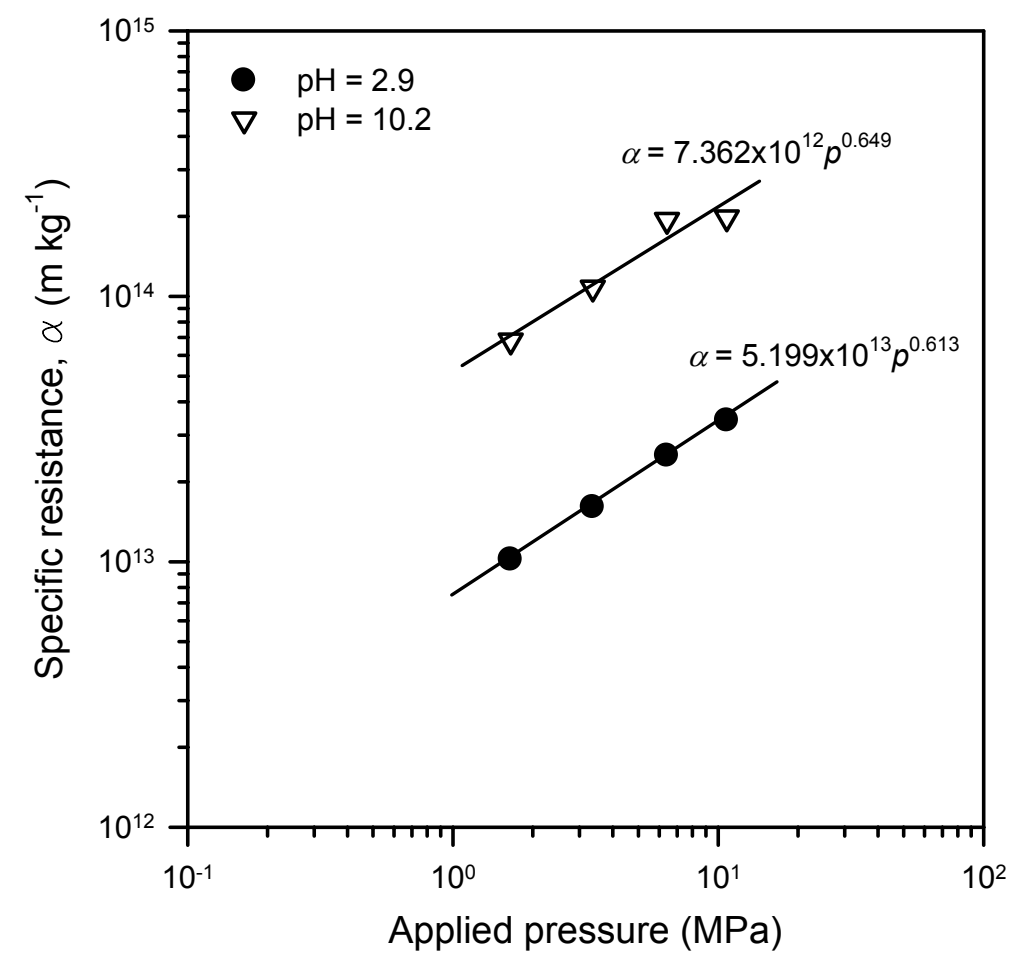

Figure 12: Dependence of specific resistance of china clay on pressure and $\mathrm{pH}\left(x_{a v}=3.3 \mu \mathrm{m}\right)$.

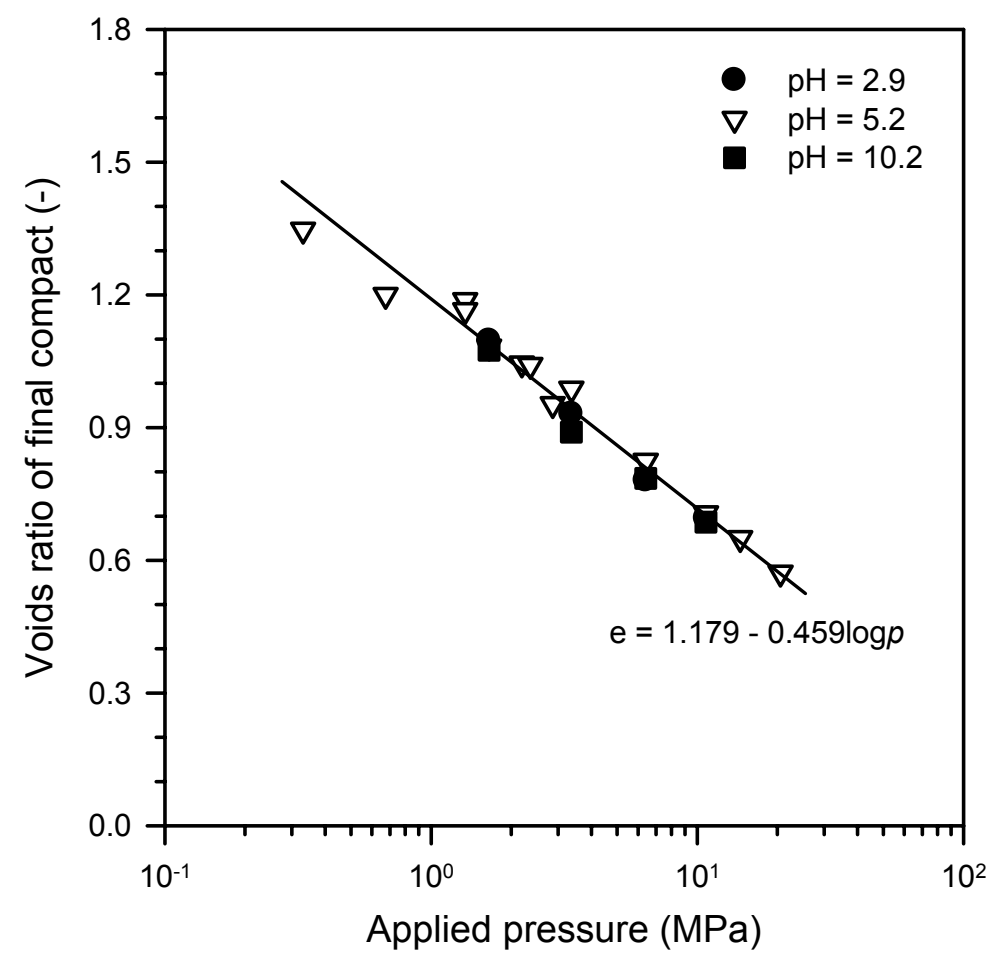

Figure 13: Dependence of ultimate voids ratio of china clay compacts on pressure and $\mathrm{pH}\left(x_{a v}=\right.$ $3.3 \mu \mathrm{m})$. 


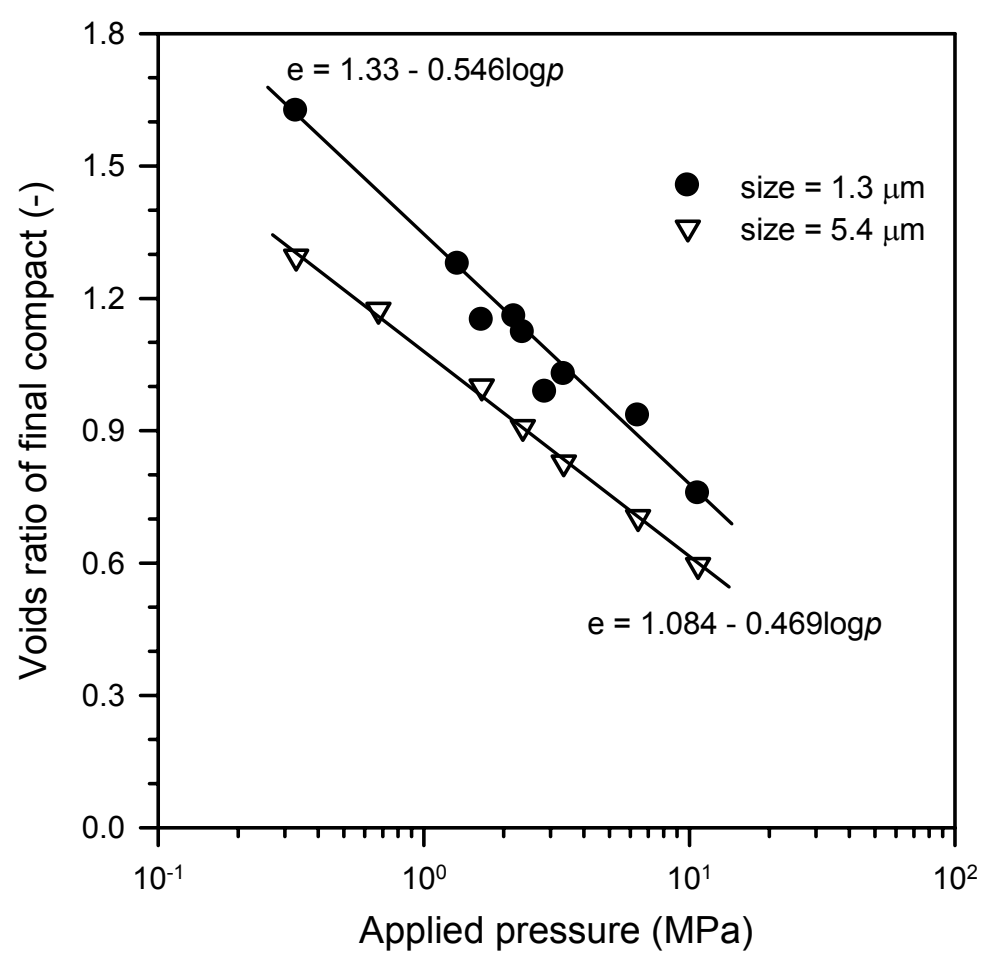

Figure 14: Dependence of ultimate voids ratio of china clay compacts on pressure and particle size $(\mathrm{pH}=5.2)$.

\begin{tabular}{|l|c|l|l|}
\hline Particle & Mean size $(\mu \mathrm{m})$ & Shape & Surface charge \\
\hline Anatase & 0.3 & ca. Tetragonal & High surface charge \\
Calcite & 3,15 & ca. Rhomboidal & Low surface charge \\
China clay & $1.3,3.3,5.4$ & Platelets & Medium-high surface charge \\
Hydromagnesite & 16.4 & ca. Rhomboidal & Medium-low surface charge \\
\hline
\end{tabular}

Table 1: General characteristics of particles used in this study. 


\begin{tabular}{|l|c|c|c|c|c|c|}
\hline Particle type & $\mathrm{pH}$ & $x_{a v}(\mu \mathrm{m})$ & $\alpha_{0}\left(\mathrm{~m} \mathrm{~kg}^{-1} \mathrm{MPa}^{-n}\right)$ & $n$ & $e_{0}$ & $b$ \\
\hline Anatase & 4.0 & 0.3 & $3.459 \times 10^{12}$ & 0.208 & 1.269 & 0.18 \\
Calcite $^{\mathrm{a}}$ & 11.8 & 3.0 & $1.288 \times 10^{12}$ & 0 & 1.161 & 0.539 \\
China clay & 2.9 & 3.3 & $7.362 \times 10^{12}$ & 0.649 & 1.198 & 0.499 \\
& 5.2 & 1.3 & $7.603 \times 10^{12}$ & 0.648 & 1.33 & 0.546 \\
& 5.2 & 3.3 & $9.506 \times 10^{12}$ & 0.458 & 1.183 & 0.446 \\
& 5.2 & 5.4 & $3.083 \times 10^{12}$ & 0.581 & 1.084 & 0.469 \\
& 5.2 & $\mathrm{Floc}^{\mathrm{b}}$ & & & 1.335 & 0.54 \\
c & 10.2 & 3.3 & $5.199 \times 10^{13}$ & 0.613 & 1.16 & 0.469 \\
Hydromagnesite & 3 to 10 & 3.3 & & & 1.179 & 0.459 \\
& 9.9 & 16.4 & $5.176 \times 10^{11}$ & 0.541 & 4.232 & 2.843 \\
\hline
\end{tabular}

\begin{tabular}{|l|c|c|c|}
\hline Particle type & $C_{e 0}\left(\mathrm{~m}^{2} \mathrm{~s}^{-1} \mathrm{MPa}^{-\mathrm{\gamma}}\right)$ & $\gamma$ & $\delta(\mathrm{MPa})$ \\
\hline Anatase & $1.48 \times 10^{-6}$ & 0 & 0 \\
Calcite $^{\mathrm{a}}$ & $2.830 \times 10^{-7}$ & 0 & 0 \\
China clay & $9.143 \times 10^{-8}$ & 0.168 & 0 \\
& $5.036 \times 10^{-8}$ & 0.263 & 0 \\
& $4.878 \times 10^{-8}$ & 0.533 & 0 \\
& $1.593 \times 10^{-7}$ & 0.116 & 0 \\
& $8.629 \times 10^{-9}$ & 0.499 & 0 \\
c & & & \\
Hydromagnesite & $2.537 \times 10^{-7}$ & -0.177 & 1.76 \\
\hline
\end{tabular}

${ }^{\text {a} A p p l i e d ~ p r e s s u r e ~ r a n g e ~} 1.3$ to $2.6 \mathrm{MPa}$

bSuspension flocculated by Magnafloc 351 (from Allied Colloids)

${ }^{\mathrm{C}}$ Only the voids ratio data for all pHs form a common line

Table 2: Coefficients of the constitutive equations for the systems studied in the applied pressure range 0.3 to $20 \mathrm{MPa}$. 